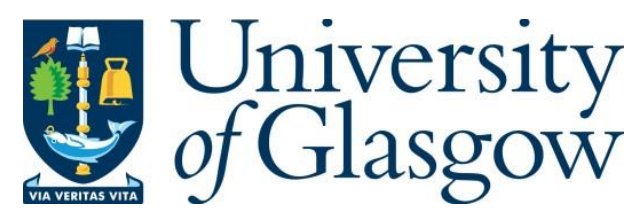

Carmona, R., Ariza, L., Cañete, A. and Muñoz-Chápuli, R. (2018) Comparative developmental biology of the cardiac inflow tract. Journal of Molecular and Cellular Cardiology, 116, pp. 155-164. (doi:10.1016/j.yjmcc.2018.02.004)

There may be differences between this version and the published version. You are advised to consult the publisher's version if you wish to cite from it.

http://eprints.gla.ac.uk/167529/

Deposited on: 11 October 2018

Enlighten - Research publications by members of the University of Glasgow http://eprints.gla.ac.uk 


\section{Comparative developmental biology of the cardiac inflow tract}

Carmona, R., Ariza L., Cañete, A., Muñoz-Chápuli, R.

Department of Animal Biology, Faculty of Science, University of Málaga, 29071 Málaga (Spain) and Andalusian Center for Nanomedicine and Biotechnology (BIONAND), Malaga, Spain.

\section{Abstract}

The vertebrate heart receives the blood through the cardiac inflow tract. This area has experienced profound changes along the evolution of vertebrates, changes that have a reflection in the cardiac ontogeny. The development of the inflow tract involves dynamic changes due to the progressive addition of tissue derived from the secondary heart field. The inflow tract is the site where the cardiac pacemaker is established and where the proepicardium develops. Differential cell migration towards the inflow tract breaks the symmetry of the primary heart tube and determines the direction of the cardiac looping. In airbreathing vertebrates an inflow tract reorganization is essential to keep separate blood flows from systemic and pulmonary returns. Finally, the sinus venosus endocardium has been recently recognized as playing a role in the constitution of the coronary vasculature. Due to this developmental complexity, congenital anomalies of the inflow tract can cause severe cardiac diseases. We aimed to review the recent literature on the cellular and molecular mechanisms that regulate the morphogenesis of the cardiac inflow tract, together with comparative and evolutionary details, thus providing a basis for a better understanding of these mechanisms.

Keywords: Cardiac inflow tract, sinus venosus, secondary heart field, proepicardium, cardiac pacemaker

\section{Abbreviations:}

\section{Introduction}

The heart is the first functional organ in the development of vertebrates, and it must grow and self-organize keeping steadily its function as a blood pump. When the heart starts to beat, it is constituted of a simple myocardial tube internally invested by the endocardium. Later, the heart tube folds, their chambers develop, sets of valves preventing backflow between chambers appear, the epicardium externally covers the myocardium and gives rise to vascular and connective tissue progenitors and it becomes eventually septated in air-breathing vertebrates. During all these processes, the blood enters the heart at the venous pole through the inflow tract, but this anatomical inlet of the heart does not retain the same nature along its development as it experiences important anatomical changes and remodeling.

The changing nature of the inflow tract is mainly due to the progressive addition of tissue to the venous pole, a process that also occurs in the outflow tract. The cell populations 
incorporating to both poles of the primary heart tube proceed from the secondary heart field (SHF), a domain of pharyngeal mesoderm placed dorsally to the heart tube. The anterior SHF gives rise to the right ventricle and outflow tract, while the posterior SHF constitutes a main part of the atrium and the central chamber of the sinus venosus (SV) (reviewed in Zaffran and Kelly, 2012). Thus, the primitive heart tube, derived from the first heart field (FHF), gives rise principally to the left ventricle. The development of the inflow tract is further complicated by the incorporation of an additional cell population that migrates from the lateral and ventral part of the cardiogenic area. This population has been called "tertiary heart field" (Bressan et al., 2013), a term that we will herein discuss. This population gives rise to the myocardium of the right and left horns of the SV that constitute the anatomical connections with the return pathway of the venous blood.

The inflow tract is also important for cardiac development since in this segment of the heart the cardiac pacemaker (sinoatrial node, SAN) develops from a restricted set of cardiomyocytes located in the sinus horns. SAN cells retain their ability to spontaneous, rhythmic depolarization and transmit regularly the stimulus for contraction to the surrounding working myocardium. The control of this restriction to a discrete and isolated population is of capital importance since ectopic foci of nodal tissue out of the SAN can trigger arrhythmias that may be clinically relevant.

A radical remodeling of the inflow tract is necessary in air-breathing vertebrates since the blood arriving to the heart originates from two sources, the venous blood from the systemic return and the oxygenated blood from the pulmonary veins that must be separated from the venous blood in its route throughout the heart. Thus, the single entry of the blood in the inflow tract shifts to a system for double blood inlet. This remodeling usually entails a strong reduction of the SV that becomes incorporated to the wall of the atrium, a chamber that also becomes divided by a septum. Developmental anomalies in the process of formation of the double inlet or the atrial septation can generate severe congenital medical conditions, as described in the last section of this review.

The SV has also been focus of attention in recent years since the endocardium of this embryonic cardiac chamber could be the source of a part of the coronary endothelium (RedHorse et al., 2010). However, the precise contribution of the SV endocardium is still controversial. Furthermore, the outer surface of the SV is the site where the proepicardium (the epicardial primordium) develops, making up another potential source of coronary progenitors (Cano et al., 2016).

For these reasons, the development of the inflow tract has generated in the last decade a high number of studies providing new information with both, basic and translational significance. We aim to provide herein a review of the cellular and molecular mechanisms regulating the development of the inflow tract, together with comparative and evolutionary details, thus providing a basis for a better understanding of these mechanisms. 


\section{The cardiac inflow tract. Comparative anatomy and development}

The basic bauplan of the vertebrate heart consists of four muscular chambers sequentially arranged, SV, atrium, ventricle and conus arteriosus. This basic layout is present in fish embryos and larvae (Figure 1). The limits between chambers are set by transversal grooves. The conus arteriosus develops valves to prevent backflow from the aorta, where blood pressure reaches its highest level. The thick-walled ventricle is responsible of generating the pressure for the circulation of blood. The thickness of the ventricular wall makes necessary the atrium to fill the ventricle. Finally, the function of the SV in the cardiac cycle is basically to constitute a blood reservoir for atrial filling (Jensen et al., 2014a). The high returning blood pressure of birds and mammals makes useless this reservoir function of the SV, that finally incorporates to the atrium.

Thus, the adult cardiac inflow tract in fish consists of a SV, receiving blood through the cardinal veins and from the liver (Figure $1 \mathrm{~A}$ ). The myocardial component of the SV is highly variable among fish species (Jensen et al., 2014a,b). In the hagfish (agnathans), the SV wall is mostly collagenic, with sparse myocardial fibers close to the sinoatrial (SA) junction (Icardo et al. 2016). In the dogfish shark the SV is completely muscular, and shows abundant subendocardial neural tissue and a fenestrated endocardium, suggesting some kind of secretory role (Muñoz-Chápuli et al 1994). The zebrafish SV virtually lacks of myocardium (Jensen et al., 2014a). In the air-breathing fish Protopterus, the SV shows myocardial walls and it is located medially and dorsally, opening in the right part of the atrium. A pulmonary vein runs across the dorsal SV carrying oxygenated blood towards the left ventricle, bypassing the SV and atrium (Icardo et al., 2005).

Adult amphibian and amniotes show in general a reduced SV with right and left anterior sinus horns receiving blood from the head and forelimbs and a right posterior sinus horn that collects blood from the posterior part of the body and the liver (Figure 2). The SV of adult mammals forms the smooth-walled portion of the right atrium, comprised between the crista terminalis (derived from the right SA valve) and the atrial septum (Figure 2) (Jensen et al., 2014a). In humans, the left horn of the SV forms the coronary sinus receiving the blood from the coronary veins. The origin of the coronary sinus in mice embryos is less clear, as it has been related with the left upper cava vein (Ciszek et al., 2007), or it could be formed by an outgrowth of the SV endocardium, as described below. Both, the Eustachian valve of the inferior vena cava and the Thebesian valve of the coronary sinus derive from the inferior rim of the right SA valve. Sizarov et al. (2010) described the development of the SV in humans, showing the similarities with the development in mice.

The SV of the lamprey embryos derives directly from the right cardinal vein at the level of the pronephros (Figure 1B). The SV of the dogfish shark embryos is muscular and relatively thick (Figure 1C) (Ramos and Macias, 1998). The muscular SA valves develop in this species by lateral infolding of the cardiac wall, being the left fold deeper than the right (Gallego et al., 1997). The SV in bony fish embryos is large and shows very thin walls (Figure 1D,E). 
In embryos of the amphibian Xenopus, systemic cardinal veins flow into a SV demarcated from the atrium by a SA ridge. The pulmonary vein connects with the left atrial side, defining a sinopulmonary fold. In later stages an interatrial ridge develops in the atrial roof and fuses with the sinopulmonary fold forming the atrial septum. Labelling of the blastomeres at the two cell stage shows that both, pulmonary vein and atrial septum originate from the left half of the body (Jahr and Manner 2011).

In chick embryos, the SV horns are continuous with the lateral vitelline veins, and they merge medially with the systemic veins to form the central part of the SV (Jensen et al., 2014a) (Figure 2). The atrium shows three expansions, the future right and left atria and the medial atrial inflow which is connected with the SV. The atrial inflow develops bilateral pulmonary pits, but only the left one connects with the developing pulmonary vein at the left of the developing atrial septum. The right part of the atrial inflow together with the $S V$ is incorporated to the right atrium, while the left atrial inflow becomes incorporated to the left atrium (Manner and Merkel, 2007). A 3D reconstruction of the development of venous pole and pulmonary veins in chick was published by Van der Berg et al. (2011).

The development of the SV in mammals, including humans, has been extensively described. The embryonic SV is composed of a medial chamber connected with the common cardinal, vitelline and umbilical veins through the sinus horns (Figure 3). After anastomosis and regressions of these veins, the SV receive the systemic blood through the upper and lower cava veins, derived from the right anterior cardinal vein and the right hepatocardiac channel, respectively (Figure 2). Cardiomyocytes derived from the right SV horn, surround the caval outlets (Jensen et al., 2014a).

The pulmonary veins (one in mice, four in humans) forms in the pulmonary mesenchyme by vasculogenesis and flow into the left atrium. They become surrounded, close to their atrial connection, by a sleeve of myocardial cells whose origin will be discussed in the next section. A general overview of the development of the mammalian venous pole was published by Douglas et al. (2011).

\section{IFT cell lineages and heart fields}

During gastrulation, cardiac progenitor cells ingress through the primitive streak and migrate to form the cardiac crescent. The first heart field progenitors are located in the anterior and lateral areas of the cardiac crescent, while the secondary heart field progenitors occupy the medial and posterior areas and remain in a proliferative progenitor state until they enter the heart (Kelly et al., 2012). In mouse embryos, the FHF expresses Nkx2.5 (a key transcription factor for cardiac development) and Islet1 by E7.5, while the SHF is characterized by the expression of Isl1 since Nkx2.5 is downregulated very soon. The FHF territories fuse in the midline, downregulate Islet1 keeping the Nkx2.5 expression, display the myocardial marker MF20 and form the primary cardiac tube by E8.0. By this time, the SHF becomes localized at the dorsal wall of the pericardial cavity and at the inlet and outlet of the cardiac tube. The SHF 
progenitors are progressively added to both extremes of the cardiac tube, upregulating Nkx2.5, downregulating Islet1 and differentiating into myocardium (Figure 4). The anterior SHF progenitors, but not those contributing to the IFT, are marked by expression of genes such as Fgf10 and Mef2c (Zaffran and Kelly, 2012). The process of addition is continuous and the expression of molecular markers of the territories is highly dynamic, so it is difficult to establish precise limits between FHF and SHF. This process is evolutionarily conserved, as evidence of a SHF contributing to both ends of the cardiac tube has been shown in zebrafish (De Pater et al., 2009; Lazic and Scott, 2010).

As mentioned above, Islet1 is expressed throughout the SHF. Its expression is dependent on canonical Wnt signaling, and it is essential for the survival, proliferation and migration of SHF progenitors (Cohen et al., 2008). Isl1 loss of function in mice is lethal at E10.5 due to defective development of both, OFT and IFT, lack of right ventricle and hypoplasic atria (Cai et al., 2003). However, in zebrafish, Isl1 is required in the venous pole only for cardiomyocyte differentiation. The Is 12 paralogue of zebrafish has two isoforms that have acquired distinct functions, Is 2 a morphant embryos shows defective looping while $|\mathrm{s}| 2 \mathrm{~b}$ participates in OFT development (Witzel et al., 2017)

On the other hand, Tbx1, a T-box transcription factor, coordinates the proliferation and expansion of SHF progenitors, and the loss of function of this factor provokes failure in the expansion of the dorsal pericardium and defects in both cardiac poles. The posterior boundary of the SHF is determined by a gradient of retinoic acid (RA), which antagonizes Tbx1 (Ryckebusch et al., 2008) and repress FGF8, an inducer of Islet1 expression (Sirbu et al., 2008; Kumar and Duester, 2014). In this way, RA signaling, promoted by RALDH2 expression in the posterior lateral mesoderm, controls the extension of the venous pole of the heart. RA treatment in chick and zebrafish leads to an expansion of the atrial/SV domain while blockade of RA signaling causes reductions in inflow tract size (Zaffran et al., 2014). In the IFT, the lack of Tbx1 leads to abnormal dorsal mesenchymal protrusion (DMP) and partially penetrants defects in the AV septation (Rana et al., 2014). The DMP is a population of mesenchymal cells that migrates through the dorsal aspect of the IFT and contributes to atrial septation. BMP signaling is essential for proliferation of DMP, as demonstrated by conditional deletion of the receptor Alk3 in SHF, that provokes impaired DMP and ostium primum defect (Briggs et al., 2013). Another T-box transcription factor, Tbx5, is expressed in the posterior SHF where it is activated by RA signaling and required for atrial septation (Xie et al., 2012)

The fate of SHF progenitors is controlled by many different signaling pathways that regulate stemness, proliferation and differentiation of the SHF progenitors, including BMPs, Hedgehog, Notch and non-canonical Wnt signals (Tian et al., 2010; Vincent and Buckingham, 2010; Kelly 2012; Xie et al., 2012). Epigenetic factors and microRNAs also play important roles in the differentiation of SHF progenitors to cardiomyocytes and other cardiac cell types (Liu and Olson, 2010). The non-canonical planar cell polarity pathway is also involved in development of the SHF. Overexpression of Wnt5a in the Isl1+ territory shortens the OFT and 
can rescue the phenotype of the Wnt5a knockout mouse embryo (Li et al., 2016).

Unfortunately, the IFT phenotype is not described in this paper. This gain of function impairs the migration of the cardiac progenitors, that remain in the SHF. Wnt11, another element of the planar cell polarity pathway, is involved in proliferation of the SHF mesenchyme, and its loss of function impairs OFT, IFT and DMP development (Van Vliet et al., 2017). A review on the Wnt signaling pathways in cardiac development has been recently published (Ruiz Villalba et al., 2016).

The SHF progenitors contributing to the IFT express PDGFR $\alpha$. Loss of function of this receptor provokes hypoplasia of the atrium and SV (Bax et al., 2010). Other alterations of the signaling mediated through PDGFR $\alpha$ also induce IFT anomalies, including a low penetrance of total anomalous pulmonary venous return (TAPVR) (Bleyl et al., 2010). Ablation of the Notch signaling pathway (through targeting of RBPJk) leads to premature myocardial differentiation of the sinus horns and also to ectopic myocardialization into the proepicardium (Del Monte et al., 2011). Finally, the orphan receptor CoupTFII is also strongly expressed in the posterior SHF, and its loss of function causes a strong reduction of the SV and part of the atrium, but the molecular mechanisms related with this receptor in cardiac development are unknown (Pereira et al., 1999).

The migration of cells from the posterolateral, ventral areas of the splanchnic mesoderm will constitute the posterior part of the SV, the sinus horns and the proepicardium (Figure 4). These cells downregulate both, Nkx2.5 and Islet1 very soon (by E7.5 in mouse and $\mathrm{HH} 4$ in chick), and express Tbx18, which is essential for the expansion and differentiation of these progenitors (Christoffels et al., 2006; Vicente-Steijn et al., 2010, Mommersteg et al., 2010, Christoffels et al., 2010). As described below, only an area of the right sinus horn, where prospective SAN will develops, keeps coexpression of Tbx18 and Islet1. Thus, the progenitors of this part of the venous pole segregate very soon from the SHF, and in this sense it has been proposed the existence of a tertiary heart field (Mommersteg et al., 2010; Bressan et al., 2013). However, other authors have considered these progenitors as a sublineage of the posterior SHF, on the basis of retrospective clonal analysis (Lescroart et al., 2012; Meilhac et al., 2014). This population is maintained by canonical Wnt signaling. When $\beta$-catenin is conditionally deleted in Tbx18+ cells the dorsal aspect of the sinus horns does not become myocardialized, although the SAN is not affected. The gain of function through stabilization of $\beta$-catenin leads to the formation of undifferentiated cell aggregates (Norden et al., 2011).

The Wilms' tumor suppressor gene (Wt1) is expressed in the proepicardium, as described below, and also in the pleuropericardial membranes, where Tbx18 is also expressed. Wt1-null mice show anomalies in the development of the sinus horns, whose myocardialization is not completed. This has been attributed to a failure in the formation of pleuropericardial membranes, since these authors found no expression of this transcription factor in sinus horns myocardium or their progenitors (Norden, 2010, 2012). We have observed that a minor part of the SV cardiomyocytes and other myocardial populations 
express Wt1 (Villa del Campo et al., 2016), but the amount of Wt1+ cardiomyocytes in the SV seems too small to account for the defects in the sinus horns (Figure 5). Non-myocardial Wt1+ cells of the IFT strongly express RALDH2 (Figure 5), contributing to the RA signaling pathway. In fact, Wt1 is a transcriptional activator of RALDH2 (Guadix et al., 2010). Thus, the function of Wt1 in the non-myocardial mesenchyme surrounding the cava veins and the sinus horns would be necessary for the development of the most posterior structures of the heart.

As stated above, the pulmonary veins connected to the left atrium show myocardial sleeves whose embryological origin was debated. Clonal studies have shown that this myocardium has not a different origin than that of the atrial myocardium (i.e. SHF), since their progenitors express Nkx2.5, Islet1, and Tbx3 but not Tbx18 (Lescroart et al., 2012).

\section{L-R asymmetry of the IFT}

The IFT becomes asymmetrical during its development (Figure 3). The transcription factor Pitx2 confers left identity to the myocardium of the left SV and atrium. Loss of function of Pitx2 provokes right atrial isomerism and double SAN. Pitx2 prevents expansion of the nodal tissue in the left sinus horn blocking the program leading to differentiation of the SAN, as described in the next section (Ammirabile et al., 2012). Tbx18 is asymmetrically expressed in the right side, and ectopic expression of this factor at the left atrium represses Pitx2. However, the loss of function of Pitx2 does not affect to the rightward cardiac looping (Greulich et al., 2016).

The SHF contributes asymmetrically to the IFT, with a larger contribution from the right side (Dominguez et al., 2012; Le Garrec et al., 2017). This asymmetry is connected with the mechanisms regulating cardiac looping. In zebrafish, the transcription factor Prrx1 is expressed asymmetrically in the lateral plate mesoderm, with a higher expression at the right side (Ocaña et al., 2017). Prrx1 loss of function leads to looping failure, mesocardia (symmetric heart tube in the midline) and defective IFT. The higher contribution of the right progenitor population shifts the venous pole at the left, thus promoting rightward looping. In chick embryos, both Prrx1 and another transcription factor related with epithelial-mesenchymal transitions, Snail1, show higher expression at the right side and are required to shift the venous pole to the left. Loss of function of any of them lead to mesocardia or randomization of looping. In mouse embryos Snail1 appears in the lateroventral mesenchyme instead of Prrx1, and its loss of function leads to looping defects. Prrx1 and Snail1 expression is induced in the right side by BMP signaling, repressing the Pitx2 pathway and providing instructive information for rightward cardiac looping (Ocaña et al., 2017).

\section{Origin and development of the SAN}

Pacemaking function is essential for a coordinated and rhythmic contraction of the cardiac muscle. In the early cardiac tube all cardiomyocytes show pacemaker potential. Along the development, the working myocardium of the chambers loses this potential, which is kept in the SAN, atrioventricular node (AVN) and conduction system, tissues in which the differentiation program of the working myocardium is repressed (Christoffels et al., 2010; 
Bakker et al., 2010). An excellent review on this issue has been recently published (Liang et al., 2017).

In zebrafish and in other teleosts where the adult SV is collagenic, the pacemaker is located in a ring-like region of the SA junction. Differently to mammals, where the pacemaker is characterized by the coexpression of Islet 1 and Tbx3, the zebrafish pacemaker expresses IsI1 and Tbx2b, but in both groups Shox 2 is essential for its development. Loss of function of Isl1 results in pacemaker dysfunction (Tessadori et al., 2012), while targeted mutation of Shox2 results in bradycardia (Blaschke et al., 2007) that can be rescued by Islet1 expression (Hoffman et al., 2013).

In chick embryos, the SAN progenitors are localized by the stage $\mathrm{HH} 8$ in a specific area of the right lateral plate mesoderm, posterior to the $\mathrm{Nkx2.5+}$ and Islet1+ territory, i.e. outside from the FHF and SHF. This area also contributes to the atrium, AV junction and proepicardium. The pacemaker fate is promoted by canonical Wnt signaling (Bressan et al., 2013). The early pacemaker activity is initially bilateral at both SV horns, then becoming restricted to the right SV, within an Nkx2.5- area expressing the ionic channel HCN4, and IsI1 and Tbx18 in an heterogeneous fashion (Vicente-Steijn et al., 2010, 2011). Part of the myocardium with these characteristics incorporates to the atrioventricular canal, where probably contributes to the AV node (Kelder et al., 2015).

There is a network of interactions in the mouse inflow tract that restricts the pacemaker activity to a very precise area (Figure 6) (Christoffels et al., 2010, reviewed in Ye et al., 2015). HCN4 is symmetrically expressed in the developing SV of mice from E8.0, although the actual pacemaker activity is first located at the left IFT by E8.5. Later, HCN4 expression extends to the right sinus horns and dorsal wall of the right atrium, being progressively restricted to the junction of the superior vena cava with the right atrium, where the pacemaker activity is located by E12.5 (Figure 5) (García Frigola et al., 2003; Christoffels et al., 2010). This change of the pacemaker activity from left to right involves also a change between two different cardiac domains (Figure 6). While the first pacemaker locates in a Nkx2.5+/Tbx18- domain of the posterior SHF, the definitive SAN head (see below) develops

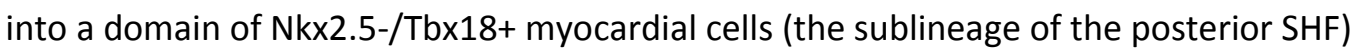
characterized by the expression of Shox 2 and Tbx3. This is concomitant with a downregulation of the HCN4 expression in the SHF, and its upregulation in the Tbx18+ domain. Loss of Islet1 expression results in hypoplasic SAN lacking Shox2, Tbx3 and HCN4 expression (Liang et al., 2015). The SAN is composed of a head and a tail that extends through the crista terminalis. The head is derived from Tbx18+ progenitors, as described above, while the tail derives from SHF progenitors (Islet1+/Tbx18-). Deletion of Tbx18 does not affect to pacemaker activity since the SAN tail can replace the head for this function (Wiese et al., 2009).

Shox 2 is essential for SAN development in mice, as described above for zebrafish, and its loss of function causes hypoplasia of SAN, leading to a lethal bradycardia. The role of Shox2 is related with direct repression of Nkx2.5, activation of Islet1 and Tbx3 (Liu et al., 2012, 
Hoffman et al., 2013). Shox 2 is induced by Tbx5 and repressed by Pitx2 in the Tbx18+ domain (Poskaric et al., 2010; Wang et al., 2014). Ectopic expression of Nkx2.5 blocks development of the SAN, while ectopic expression of Shox 2 in the working myocardium leads to cardiac malformation, but not ectopic SAN, suggesting that Shox2 is necessary but not sufficient to display the SAN program (Espinoza-Lewis et al., 2011). Conditional deletion of Shox2 only in the SAN tail/periphery (where Nkx2.5 is expressed) using an Nkx2.5-Cre driver results in downregulation of Tbx3, HCN4 and IsI1, and ectopic Cx40 activation (Hoffman et al., 2013; Liang et al., 2017). These adult mutant mice exhibit sick sinus syndrome, i.e. severe bradycardia, arrhythmia and SA block.

Tbx3 represses the working myocardium program in SAN and conduction system (Bakker et al., 2010) and its loss of function is lethal by midgestation. The mutant embryos show normal SAN size, HCN4 expression and cardiac rhythm, but ectopic Cx43, Cx40 and Nppa expression in the SAN (Hoogars et al., 2007). Even Tbx3 hypomorphs suffer of lethal arrhythmias (Frank et al., 2012). When Tbx3 is ectopically expressed in the atrium with a Nppa-Cre driver, ectopic pacemaker foci appear (Hoogars et al., 2007), but overexpression in adult myocardium does not cause the same effect, although it downregulates working myocardium genes (Bakker et al., 2012)

Thus, the myocardium derived from the Islet1+/Tbx18+/Nkx2.5- mesenchyme, is essential for the setting of the definitive pacemaker in mammals. Forced expression of Tbx18 is able to reprogramming ventricular cardiomyocytes in rat and pig towards a SAN phenotype. However, in mouse, misexpression of Tbx18 under control of a Myh6 promoter causes dilated atria with thickened walls, reduction of the right ventricle, septal defects and lethality, but not ectopic expression of SAN markers. The working myocardium program results only partially inhibited. Thus, Tbx18 inhibition is necessary for working myocardium development but its expression does not revert this myocardium towards a SAN phenotype (Greulich et al., 2016).

In the myocardium of the pulmonary veins, expression of Shox2 inhibits Nkx2.5. This myocardium expresses HCN4 and when isolated in culture show pacemaker activity. Deletion of Shox2 in pulmonary vein myocardium leads to downregulation of $\mathrm{HCN} 4$, but not in an Nkx2.5 hypomorph, that rescues the requirement of Shox 2 for HCN4 expression (Ye et al., 2015). These observations are clinically relevant by the implication of the pulmonary vein myocardium in the generation of arrhythmias and atrial fibrillation, as described below.

\section{The proepicardium, the SV endocardium and the origin of the coronary vessels}

The proepicardium is a cluster of coelomic epithelium and mesenchymal cells that migrate over the myocardium and constitute the epicardium (Figure 3). Mesenchymal cells derived from the epicardium invade the myocardium and contribute to cardiac vascular and connective tissue. The proepicardium and the Tbx18+ myocardial progenitors of the SV share a common lineage. The proepicardial or myocardial fate of this lineage is regulated by FGF and BMP signaling, respectively (Van Wijk et al., 2009), and also by Notch signaling, as described 
above. The epicardial formation depends on Cdc42 expression, that regulates trafficking of FGF receptors to the cell membrane of proepicardial and epicardial cells (Li et al., 2017).

The smooth muscle of the coronary arteries is derived mainly from mesenchymal cells derived from the embryonic epicardium (Dueñas et al., 2017), with a minor contribution of neural crest cells in the proximal areas (Jiang et al., 2000). However, the origin of the coronary endothelium has been more controversial. Both, proepicardial and ventricular endocardial cells have been claimed as contributors to the endothelium of the coronary vessels (Katz et al., 2012; Wu et al., 2012; Tian et al., 2013; Zhang et al., 2016), but a key issue is the contribution of the SV endocardium to the coronary endothelium. The SV could produce angiogenic sprouts that would dedifferentiate giving rise to arteries and capillaries within the ventricles, and surface veins (Red Horse et al., 2010). Angiogenic sprouts induced by VEGFc secreted by the epicardium would vascularize the dorsal and lateral aspects of the ventricles, while the ventral aspect and the interventricular septum become vascularized by endocardial cells (Chen et al., 2014). Other report has described heterogeneity in the endocardium of the SV and the dependence of the cardiac veins (not the arteries) on angiopoietin-1. Cells negative for apelin receptor (APJ) would give rise to veins, in an angiopoietin-1 dependent fashion (Arita et al., 2014). A recent study using a driver that is active in the proepicardium shows that proepicardial cells give rise to a fraction of the coronary endothelium (about 20\%) (Cano et al. 2016). Thus, either through the SV endocardium or through the proepicardium the IFT plays a role in the emergence of the coronary endothelium.

The emergence of vessels from the SV endocardium during development might be related with the peculiar evolution of the cardiac vascularization. In small and less active fishes, the heart lacks of compact myocardium, and the blood flows throughout the intertrabecular sinusoids. A primitive mechanism to improve the blood supply to this myocardium is the connection of these sinusoids to a network of subepicardial vessels flowing into the SV (Figure 7) (De Andrés et al., 1993). In larger and more active fish, a compact ventricular myocardium develops, but it requires oxygenated blood, and this can only be provided by hypobranchial branches from the efferent branchial arteries. Thus, as shown for the dogfish shark development, cardiac veins develop independently of the coronary arteries as SV outgrowths (De Andrés et al., 1993). This origin of arteries and veins might explain the heterogeneous origin of the coronary endothelium.

\section{Developmental anomalies of IFT and disease}

The high complexity of the IFT development is related with a number of congenital anomalies of clinical relevance. We will briefly describe the main features of these anomalies and their relation with the development of the IFT.

The systemic blood return is normally performed through the cava veins, connected with the right atrium through the remains of the right sinus horn. According to Mazzuco et al. (1990), anomalies can consist of left upper cava connected to the coronary sinus or to the left 
atrium, right superior vena cava or inferior vena cava draining into the left atrium or total anomalous systemic venous connection to the left atrium, which is usually combined with atrial isomerism.

The anomalies in the development of the pulmonary veins have been reviewed by Douglas (2011). These anomalies can be related with IFT maldevelopment in the case of right atrial isomerism (with inhibition of left atrium features), or defective development of the DMP, leading to a rightward shift of the pulmonary veins, that would drain into the SV. We will describe below that defects in atrial septation are frequently associated to anomalous connection of pulmonary veins. We have also described above that alterations of PDGFR $\alpha$ signaling induce IFT anomalies and TAPVR (Bleyl et al., 2010).

Cor triatriatum dexter is an extremely rare condition that has been considered as an anomalous venous connection, but it is caused by the persistence of the embryonic right SV valve. Thus, the right atrium is abnormally divided by a fibromuscular septum. This malformation increases the risk of arrhythmias, including atrial fibrillation (Choudhary et al., 2013). When the valve appears in adults as a highly fenestrated membrane, not impeding blood flow, it is known as the Chiari network, that appears in $2 \%$ of the population.

Atrial isomerism is normally associated to heterotaxy, the abnormal arrangement of the internal organs across the left-right axis of the body. Within heterotaxy we can distinguish isomerism of the right atrium or of the left atrium, usually associated to asplenia or polysplenia. The IFT defects found in heterotaxy can include single atrium/atrial septal defect, total/partial anomalous pulmonary venous return and multiple sinus nodes (Anderson et al., 2015).

The atrial septal defect (ASD) is the most common congenital heart defect, accounting for up to $15 \%$ of all adult cases of these anomalies. There are different types of ASD, some of them are related with the process of septation on the atrium (ostium primum and ostium secundum atrial septal defects and patent foramen ovale). Haploinsufficiency of Tbx5 causes the HoltOram syndrome, characterized by multiple abnormalities including atrial septal defects (Bruneau et al., 1999). SV atrial septal defect is a deficiency of the wall between the superior vena cava and the right-sided pulmonary veins. This defect is almost always associated with partial anomalous return of the pulmonary veins. The lest common form of ASD involves unroofing of the coronary sinus, which results in shunting into the left atrium (Briggs et al., 2012; Anderson et al., 2015; Jensen et al., 2017).

Human SAN dysfunction or sick sinus syndrome, is a group of disorders of the cardiac rhythm, characterized by episodes of sinus bradycardia or tachycardia and SA arrest/block. Its pathophysiology is unclear, but a number of murine models have shown similarities with this condition after alteration of the genetic network leading to SAN development as described above (Liang et al., 2017). 
Ectopic foci of pacemaker activity can develop in myocardial derivatives of the IFT, basically the myocardial sleeves of the pulmonary veins and the superior cava vein. Defects in the development of these myocardial areas can be related with this ectopic activity that can produce atrial fibrillation (De Simone et al., 2012).

\section{Concluding remarks}

The even increase in the number of papers on the IFT development published in recent years highlights the interest of the scientific community to this issue. The cardiac IFT experiences a complex and highly dynamic development, and it is involved in different functions related with cardiac performance, L-R asymmetry, chamber septation, electrical activity and formation of non-myocardial tissues. Despite this intensive research, many questions remain unanswered, particularly those related with the different cell lineages contributing to the IFT. We think that comparative approaches can be valuable to understand these fascinating developmental processes.

\section{Acknowledgments}

We thank David Navas (SCAI, University of Málaga) for technical help with confocal microscopy and flow cytometry and Laura Montiel for designing the cartoons. This work was supported by the Spanish Ministry of Economy and Competitiveness under Grant BFU2014-52299-P and Instituto de Salud Carlos III-TERCEL network under Grant RD12/0019-0022.

\section{References}

J. van der Geer, J.A.J. Hanraads, R.A. Lupton, The art of writing a scientific article, J. Sci. Commun. 163 (2010) 51-59.

Ammirabile G, Tessari A, Pignataro V, Szumska D, Sutera Sardo F, Benes J Jr, Balistreri M, Bhattacharya S, Sedmera D, Campione M. Pitx2 confers left morphological, molecular, and functional identity to the sinus venosus myocardium. Cardiovasc. Res. 2012;93(2):291-301. doi: $10.1093 / c v r / c v r 314$.

Anderson RH, Brown NA, Mohun T. Insights regarding the normal and abnormal formation of the atrial and ventricular septal structures. J. Clin. Anat. 2016;29(3):290-304. doi: 10.1002/ca.22627.

Arita Y, Nakaoka Y, Matsunaga T, Kidoya H, Yamamizu K, Arima Y, Kataoka-Hashimoto T, Ikeoka K, Yasui T, Masaki T, Yamamoto K, Higuchi K, Park JS, Shirai M, Nishiyama K, Yamagishi H, Otsu K, Kurihara H, Minami T, Yamauchi-Takihara K, Koh GY, Mochizuki N, Takakura N, Sakata Y, Yamashita JK, Komuro I. Myocardium-derived angiopoietin-1 is essential for coronary vein formation in the developing heart. Nat Commun. 2014;5:4552. doi: $10.1038 /$ ncomms5552. 
Bakker ML, Christoffels VM, Moorman AF.The cardiac pacemaker and conduction system develops from embryonic myocardium that retains its primitive phenotype. J. Cardiovasc. Pharmacol. 2010;56(1):6-15. doi: 10.1097/FJC.0b013e3181e775d3.

Bakker ML, Boink GJ, Boukens BJ, Verkerk AO, van den Boogaard M, den Haan AD, Hoogaars WM, Buermans HP, de Bakker JM, Seppen J, Tan HL, Moorman AF, 't Hoen PA, Christoffels VM.T-box transcription factor TBX3 reprogrammes mature cardiac myocytes into pacemaker-like cells. Cardiovasc Res. 2012;94(3):439-49. doi: 10.1093/cvr/cvs120.

Bax NA, Bleyl SB, Gallini R, Wisse LJ, Hunter J, Van Oorschot AA, Mahtab EA, Lie-Venema H, Goumans MJ, Betsholtz C, Gittenberger-de Groot AC. Cardiac malformations in Pdgfralpha mutant embryos are associated with increased expression of WT1 and Nkx2.5 in the second heart field. Dev Dyn. 2010 Aug;239(8):2307-17. doi: 10.1002/dvdy.22363.

Blaschke RJ, Hahurij ND, Kuijper S, Just S, Wisse LJ, Deissler K, Maxelon T, Anastassiadis K, Spitzer J, Hardt SE, Schöler H, Feitsma H, Rottbauer W, Blum M, Meijlink F, Rappold G, Gittenberger-de Groot AC. Targeted mutation reveals essential functions of the homeodomain transcription factor Shox 2 in sinoatrial and pacemaking development. Circulation. 2007;115(14):1830-8.

Bleyl SB, Saijoh Y, Bax NA, Gittenberger-de Groot AC, Wisse LJ, Chapman SC, Hunter J, Shiratori H, Hamada H, Yamada S, Shiota K, Klewer SE, Leppert MF, Schoenwolf GC. Dysregulation of the PDGFRA gene causes inflow tract anomalies including TAPVR: integrating evidence from human genetics and model organisms. Hum Mol Genet. 2010;19(7):1286-301. doi: 10.1093/hmg/ddq005.

Bressan M, Liu G, Mikawa T. Early mesodermal cues assign avian cardiac pacemaker fate potential in a tertiary heart field. Science. 2013;340(6133):744-8. doi: 10.1126/science.1232877.

Briggs LE, Kakarla J, Wessels A. The pathogenesis of atrial and atrioventricular septal defects with special emphasis on the role of the dorsal mesenchymal protrusion. Differentiation. 2012;84(1):117-30. doi: 10.1016/j.diff.2012.05.006.

Briggs LE, Phelps AL, Brown E, Kakarla J, Anderson RH, van den Hoff MJ, Wessels A. Expression of the BMP receptor Alk3 in the second heart field is essential for development of the dorsal mesenchymal protrusion and atrioventricular septation. Circ Res. 2013 May 24;112(11):1420-32. doi: 10.1161/CIRCRESAHA.112.300821.

Bruneau BG, Logan M, Davis N, Levi T, Tabin CJ, Seidman JG, Seidman CE. Chamber-specific cardiac expression of Tbx5 and heart defects in Holt-Oram syndrome. Dev Biol. 1999;211(1):100-8.

Cai CL, Liang X, Shi Y, Chu PH, Pfaff SL, Chen J, Evans S.Isl1 identifies a cardiac progenitor population that proliferates prior to differentiation and contributes a majority of cells to the heart. Dev Cell. 2003;5(6):877-89. 
Cano E, Carmona R, Ruiz-Villalba A, Rojas A, Chau YY, Wagner KD, Wagner N, Hastie ND, Muñoz-Chápuli R, Pérez-Pomares JM. Extracardiac septum transversum/proepicardial endothelial cells pattern embryonic coronary arterio-venous connections. Proc Natl Acad Sci U S A. 2016;113(3):656-61. doi: 10.1073/pnas.1509834113.

Chen HI, Sharma B, Akerberg BN, Numi HJ, Kivelä R, Saharinen P, Aghajanian H, McKay AS, Bogard PE, Chang AH, Jacobs AH, Epstein JA, Stankunas K, Alitalo K, Red-Horse K. The sinus venosus contributes to coronary vasculature through VEGFC-stimulated angiogenesis. Development. 2014;141(23):4500-12. doi: 10.1242/dev.113639.

Choudhary D, Sivasankaran S, Venkateshwaran S, Sasidharan B.Cor triatriatum dexter: a rare cause of isolated right atrial enlargement. Pediatr Cardiol. 2013;34(1):198-9. doi: 10.1007/s00246-012-0443-0.

Christoffels VM, Mommersteeg MT, Trowe MO, Prall OW, de Gier-de Vries C, Soufan AT, Bussen M, Schuster-Gossler K, Harvey RP, Moorman AF, Kispert A. Formation of the venous pole of the heart from an Nkx2-5-negative precursor population requires Tbx18. Circ Res. 2006;98(12):1555-63

Christoffels VM, Smits GJ, Kispert A, Moorman AF. Development of the pacemaker tissues of the heart. Circ Res. 2010;106(2):240-54. doi: 10.1161/CIRCRESAHA.109.205419

Ciszek B, Skubiszewska D, Ratajska A. The anatomy of the cardiac veins in mice. J Anat. 2007;211(1):53-63.

Cohen ED, Tian Y, Morrisey EE. Wnt signaling: an essential regulator of cardiovascular differentiation, morphogenesis and progenitor self-renewal. Development. 2008;135(5):789-98. doi: 10.1242/dev.016865.

De Andrés AV, Muńoz-Chápuli R, Sans-Coma V. Development of the coronary arteries and cardiac veins in the dogfish (Scyliorhinus canicula). Anat Rec. 1993;235(3):436-42.

de Pater E, Clijsters L, Marques SR, Lin YF, Garavito-Aguilar ZV, Yelon D, Bakkers J.Distinct phases of cardiomyocyte differentiation regulate growth of the zebrafish heart.

Development. 2009;136(10):1633-41. doi: 10.1242/dev.030924.

DeSimone CV, Noheria A, Lachman N, Edwards WD, Gami AS, Maleszewski JJ, Friedman PA, Munger TM, Hammill SC, Packer DL, Asirvatham SJ. Myocardium of the superior vena cava, coronary sinus, vein of Marshall, and the pulmonary vein ostia: gross anatomic studies in 620 hearts. J Cardiovasc Electrophysiol. 2012;23(12):1304-9. doi: 10.1111/j.15408167.2012.02403.x.

del Monte G, Casanova JC, Guadix JA, MacGrogan D, Burch JB, Pérez-Pomares JM, de la Pompa JL.Differential Notch signaling in the epicardium is required for cardiac inflow development and coronary vessel morphogenesis. Circ Res. 2011;108(7):824-36. doi: 10.1161/CIRCRESAHA.110.229062.

Domínguez JN, Meilhac SM, Bland YS, Buckingham ME, Brown NA. Asymmetric fate of the posterior part of the second heart field results in unexpected left/right contributions to 
both poles of the heart. Circ Res. 2012;111(10):1323-35. doi:

10.1161/CIRCRESAHA.112.271247. Epub 2012 Sep 5.

Douglas YL, Jongbloed MR, Deruiter MC, Gittenberger-de Groot AC. Normal and abnormal development of pulmonary veins: state of the art and correlation with clinical entities.

Int J Cardiol. 2011;147(1):13-24. doi: 10.1016/j.ijcard.2010.07.004.

Dueñas A, Aranega AE, Franco D. More than Just a Simple Cardiac Envelope; Cellular Contributions of the Epicardium. Front Cell Dev Biol. 2017;5:44. doi: 10.3389/fcell.2017.00044.

Espinoza-Lewis RA, Liu H, Sun C, Chen C, Jiao K, Chen Y.Ectopic expression of Nkx2.5 suppresses the formation of the sinoatrial node in mice. Dev Biol. 2011;356(2):359-69. doi: 10.1016/j.ydbio.2011.05.663.

Frank DU, Carter KL, Thomas KR, Burr RM, Bakker ML, Coetzee WA, Tristani-Firouzi M, Bamshad MJ, Christoffels VM, Moon AM. Lethal arrhythmias in Tbx3-deficient mice reveal extreme dosage sensitivity of cardiac conduction system function and homeostasis. Proc Natl Acad Sci U S A. 2012;109(3):E154-63. doi: 10.1073/pnas.1115165109.

Gallego A, Durán AC, De Andrés AV, Navarro P, Muñoz-Chápuli R. Anatomy and development of the sinoatrial valves in the dogfish (Scyliorhinus canicula). Anat Rec. 1997;248(2):224-32.

Garcia-Frigola C, Shi Y, Evans SM. Expression of the hyperpolarization-activated cyclic nucleotide-gated cation channel HCN4 during mouse heart development. Gene Expr Patterns. 2003;3(6):777-83.

Greulich $F(1)$, Trowe MO(1), Leffler A(2), Stoetzer C(2), Farin HF(1), Kispert A(3).

Misexpression of Tbx18 in cardiac chambers of fetal mice interferes with chamber-specific developmental programs but does not induce a pacemaker-like gene signature. J Mol Cell Cardiol. 2016;97:140-9. doi: 10.1016/j.yjmcc.2016.05.004.

Guadix JA, Ruiz-Villalba A, Lettice L, Velecela V, Muñoz-Chápuli R, Hastie ND, Pérez-Pomares JM, Martínez-Estrada OM. Wt1 controls retinoic acid signalling in embryonic epicardium through transcriptional activation of Raldh2. Development. 2011;138(6):1093-7. doi: 10.1242/dev.044594.

Hoffmann S1, Berger IM, Glaser A, Bacon C, Li L, Gretz N, Steinbeisser H, Rottbauer W, Just S, Rappold G. Islet1 is a direct transcriptional target of the homeodomain transcription factor Shox2 and rescues the Shox2-mediated bradycardia. Basic Res Cardiol. 2013;108(2):339. doi: 10.1007/s00395-013-0339-z.

Hoogaars WM, Engel A, Brons JF, Verkerk AO, de Lange FJ, Wong LY, Bakker ML, Clout DE, Wakker V, Barnett P, Ravesloot JH, Moorman AF, Verheijck EE, Christoffels VM. Tbx3 controls the sinoatrial node gene program and imposes pacemaker function on the atria. Genes Dev. 2007;21(9):1098-112. 
Icardo JM, Colvee E, Schorno S, Lauriano ER, Fudge DS, Glover CN, Zaccone G. Morphological analysis of the hagfish heart. II. The venous pole and the pericardium. J Morphol. 2016;277(7):853-65. doi: 10.1002/jmor.20539.

Icardo JM, Ojeda JL, Colvee E, Tota B, Wong WP, Ip YK. Heart inflow tract of the African lungfish Protopterus dolloi. J Morphol. 2005;263(1):30-8.

Jahr M, Männer J. Development of the venous pole of the heart in the frog Xenopus laevis: a morphological study with special focus on the development of the venoatrial connections. Dev Dyn. 2011 Jun;240(6):1518-27. doi: 10.1002/dvdy.22611.

Jensen B, Boukens BJD, Wang T, Moorman AFM, Christoffels VM. Evolution of the Sinus Venosus from Fish to Human. J. Cardiovasc. Dev. Dis. 2014;1(1), 14-28. doi:10.3390/jcdd1010014

Jensen B, Moorman AF, Wang T. Structure and function of the hearts of lizards and snakes. Biol Rev Camb Philos Soc. 2014;89(2):302-36. doi: 10.1111/brv.12056.

Jensen B, Spicer DE, Sheppard MN, Anderson RH.Development of the atrial septum in relation to postnatal anatomy and interatrial communications. Heart. 2017;103(6):456-462. doi: 10.1136/heartjnl-2016-310660

Jiang X, Rowitch DH, Soriano P, McMahon AP, Sucov HM. Fate of the mammalian cardiac neural crest. Development. 2000;127(8):1607-16.

Katz TC, Singh MK, Degenhardt K, Rivera-Feliciano J, Johnson RL, Epstein JA, Tabin CJ. Distinct compartments of the proepicardial organ give rise to coronary vascular endothelial cells. Dev Cell. 2012;22(3):639-50. Doi: 10.1016/j.devcel.2012.01.012.

Kelder TP, Vicente-Steijn R, Harryvan TJ, Kosmidis G, Gittenberger-de Groot AC, Poelmann RE, Schalij MJ, DeRuiter MC, Jongbloed MR. The sinus venosus myocardium contributes to the atrioventricular canal: potential role during atrioventricular node development? J Cell Mol Med. 2015;19(6):1375-89. doi: 10.1111/jcmm.12525.

Kelly RG. The second heart field. Curr Top Dev Biol. 2012;100:33-65. doi: 10.1016/B978-0-12387786-4.00002-6.

Kumar S, Duester G. Retinoic acid controls body axis extension by directly repressing Fgf8 transcription. Development. 2014;141(15):2972-7. doi: 10.1242/dev.112367.

Lazic S, Scott IC. Mef2cb regulates late myocardial cell addition from a second heart field-like population of progenitors in zebrafish. Dev Biol. 2011;354(1):123-33. doi: 10.1016/j.ydbio.2011.03.028.

Le Garrec JF, Domínguez JN, Desgrange A, Ivanovitch KD, Raphaël E, Bangham JA, Torres M, Coen E, Mohun TJ, Meilhac SM. A predictive model of asymmetric morphogenesis from 3D reconstructions of mouse heart looping dynamics. Elife. 2017;6. pii: e28951. doi: 10.7554/eLife.28951. 
Lescroart F, Mohun T, Meilhac SM, Bennett M, Buckingham M.Lineage tree for the venous pole of the heart: clonal analysis clarifies controversial genealogy based on genetic tracing. Circ Res. 2012;111(10):1313-22. doi: 10.1161/CIRCRESAHA.112.271064.

Li D, Sinha T, Ajima R, Seo HS, Yamaguchi TP, Wang J. Spatial regulation of cell cohesion by Wnt5a during second heart field progenitor deployment. Dev Biol. 2016;412(1):18-31. doi: 10.1016/j.ydbio.2016.02.017

Li J, Miao L, Zhao C, Shaikh Qureshi WM, Shieh D, Guo H, Lu Y, Hu S, Huang A, Zhang L, Cai CL, Wan LQ, Xin H, Vincent P, Singer HA, Zheng Y, Cleaver O, Fan ZC, Wu M. CDC42 is required for epicardial and pro-epicardial development by mediating FGF receptor trafficking to the plasma membrane. Development. 2017;144(9):1635-1647. doi: 10.1242/dev.147173.

Liang X, Zhang Q, Cattaneo P, Zhuang S, Gong X, Spann NJ, Jiang C, Cao X, Zhao X, Zhang X, Bu L, Wang G, Chen HS, Zhuang T, Yan J, Geng P, Luo L, Banerjee I, Chen Y, Glass CK, Zambon AC, Chen J, Sun Y, Evans SM. Transcription factor ISL1 is essential for pacemaker development and function. J Clin Invest. 2015;125(8):3256-68. doi: 10.1172/JCI68257.

Liang X, Evans SM, Sun Y. Development of the cardiac pacemaker. Cell Mol Life Sci. 2017;74(7):1247-1259. doi: 10.1007/s00018-016-2400-1.

Liu N, Olson EN. MicroRNA regulatory networks in cardiovascular development. Dev Cell. 2010;18(4):510-25. doi: 10.1016/j.devcel.2010.03.010

Liu H, Espinoza-Lewis RA, Chen C, Hu X, Zhang Y, Chen Y. The role of Shox2 in SAN development and function. Pediatr Cardiol. 2012;33(6):882-9. doi: 10.1007/s00246-0120179-x.

Männer J, Merkel N. Early morphogenesis of the sinuatrial region of the chick heart: a contribution to the understanding of the pathogenesis of direct pulmonary venous connections to the right atrium and atrial septal defects in hearts with right isomerism of the atrial appendages. Anat Rec (Hoboken). 2007;290(2):168-80.

Mazzucco A, Bortolotti U, Stellin G, Gallucci V. Anomalies of the systemic venous return: a review. J Card Surg. 1990;5(2):122-33

Meilhac SM, Lescroart F, Blanpain C, Buckingham ME. Cardiac cell lineages that form the heart. Cold Spring Harb Perspect Med. 2014;4(9):a013888. doi: 10.1101/cshperspect.a013888.

Mommersteeg MT, Domínguez JN, Wiese C, Norden J, de Gier-de Vries C, Burch JB, Kispert A, Brown NA, Moorman AF, Christoffels VM.The sinus venosus progenitors separate and diversify from the first and second heart fields early in development. Cardiovasc Res. 2010;87(1):92-101. doi: 10.1093/cvr/cvq033.

Muñoz-Chápuli R, De Andrés V, Ramos C.Tachykinin-like immunoreactivity in the sinus venosus of the dogfish (Scyliorhinus canicula). Cell Tissue Res 1994;278:171-175.

Norden J(1), Grieskamp T, Christoffels VM, Moorman AF, Kispert A. Partial absence of pleuropericardial membranes in Tbx18- and Wt1-deficient mice. PLoS One. 2012;7(9):e45100. doi: 10.1371/journal.pone.0045100. 
Norden J, Greulich F, Rudat C, Taketo MM, Kispert A. Wnt/ $\beta$-catenin signaling maintains the mesenchymal precursor pool for murine sinus horn formation. Circ Res. 2011;109(6):e4250. doi: 10.1161/CIRCRESAHA.111.245340.

Norden J, Grieskamp T, Lausch E, van Wijk B, van den Hoff MJ, Englert C, Petry M, Mommersteeg MT, Christoffels VM, Niederreither K, Kispert A. Wt1 and retinoic acid signaling in the subcoelomic mesenchyme control the development of the pleuropericardial membranes and the sinus horns. Circ Res. 2010;106(7):1212-20. doi:

10.1161/CIRCRESAHA.110.217455.

Ocaña OH, Coskun H, Minguillón C, Murawala P, Tanaka EM, Galcerán J, Muñoz-Chápuli R, Nieto MA. A right-handed signalling pathway drives heart looping in vertebrates. Nature. 2017;549(7670):86-90. doi: 10.1038/nature23454.

Pereira FA, Qiu Y, Zhou G, Tsai MJ, Tsai SY. The orphan nuclear receptor COUP-TFIl is required for angiogenesis and heart development. Genes Dev. 1999;13(8):1037-49.

Puskaric S, Schmitteckert S, Mori AD, Glaser A, Schneider KU, Bruneau BG, Blaschke RJ, Steinbeisser H, Rappold G. Shox2 mediates Tbx5 activity by regulating Bmp4 in the pacemaker region of the developing heart. Hum Mol Genet. 2010;19(23):4625-33. doi: $10.1093 / \mathrm{hmg} / \mathrm{ddq} 393$

Ramos C, Macías D. Ultrastructural study of the sinus venosus in embryos of the dogfish (Scyliorhinus canicula). Anat Embryol (Berl). 1998;198(6):523-36.

Rana MS, Théveniau-Ruissy M, De Bono C, Mesbah K, Francou A, Rammah M, Domínguez JN, Roux M, Laforest B, Anderson RH, Mohun T, Zaffran S, Christoffels VM, Kelly RG. Tbx1 coordinates addition of posterior second heart field progenitor cells to the arterial and venous poles of the heart. Circ Res. 2014;115(9):790-9. doi:

10.1161/CIRCRESAHA.115.305020.

Red-Horse K(1), Ueno H, Weissman IL, Krasnow MA. Coronary arteries form by developmental reprogramming of venous cells.Nature. 2010;464(7288):549-53. doi: 10.1038/nature08873.

Ruiz-Villalba A(1), Hoppler S(2), van den Hoff MJ. Wnt signaling in the heart fields: Variations on a common theme. Dev Dyn. 2016;245(3):294-306. doi: 10.1002/dvdy.24372.

Ryckebusch L, Wang Z, Bertrand N, Lin SC, Chi X, Schwartz R, Zaffran S, Niederreither K. Retinoic acid deficiency alters second heart field formation. Proc Natl Acad Sci U S A. 2008;105(8):2913-8. doi: 10.1073/pnas.0712344105.

Sirbu IO, Zhao X, Duester G. Retinoic acid controls heart anteroposterior patterning by downregulating IsI1 through the Fgf8 pathway. Dev Dyn. 2008;237(6):1627-35. doi: 10.1002/dvdy.21570.

Sizarov A, Anderson RH, Christoffels VM, Moorman AF. Three-dimensional and molecular analysis of the venous pole of the developing human heart. Circulation. 2010;122(8):798807. doi: 10.1161/CIRCULATIONAHA.110.953844. 
Tessadori F, van Weerd JH, Burkhard SB, Verkerk AO, de Pater E, Boukens BJ, Vink A, Christoffels VM, Bakkers J. Identification and functional characterization of cardiac pacemaker cells in zebrafish. PLoS One. 2012;7(10):e47644. doi:

10.1371/journal.pone.0047644.

Tian X, Hu T, Zhang H, He L, Huang X, Liu Q, Yu W, He L, Yang Z, Zhang Z, Zhong TP, Yang X, Yang Z, Yan Y, Baldini A, Sun Y, Lu J, Schwartz RJ, Evans SM, Gittenberger-de Groot AC, RedHorse K, Zhou B. Subepicardial endothelial cells invade the embryonic ventricle wall to form coronary arteries. Cell Res. 2013;23(9):1075-90. doi: 10.1038/cr.2013.83.

Tian Y, Yuan L, Goss AM, Wang T, Yang J, Lepore JJ, Zhou D, Schwartz RJ, Patel V, Cohen ED, Morrisey EE.Characterization and in vivo pharmacological rescue of a Wnt2-Gata6 pathway required for cardiac inflow tract development. Dev Cell. 2010;18(2):275-87. doi: 10.1016/j.devcel.2010.01.008.

Van den Berg G, Moorman AF. Development of the pulmonary vein and the systemic venous sinus: an interactive 3D overview. PLoS One. 2011;6(7):e22055. doi:

10.1371/journal.pone.0022055.

Van Vliet PP, Lin L, Boogerd CJ, Martin JF, Andelfinger G, Grossfeld PD, Evans SM. Tissue specific requirements for WNT11 in developing outflow tract and dorsal mesenchymal protrusion. Dev Biol. 2017;pii: S0012-1606(17)30119-7. doi: 10.1016/j.ydbio.2017.06.021. [Epub ahead of print]

Van Wijk B, van den Berg G, Abu-Issa R, Barnett P, van der Velden S, Schmidt M, Ruijter JM, Kirby ML, Moorman AF, van den Hoff MJ. Epicardium and myocardium separate from a common precursor pool by crosstalk between bone morphogenetic protein- and fibroblast growth factor-signaling pathways. Circ Res. 2009;105(5):431-41. doi:

10.1161/CIRCRESAHA.109.203083

Vicente-Steijn R, Kolditz DP, Mahtab EA, Askar SF, Bax NA, VAN DER Graaf LM, Wisse L, Passier R, Pijnappels DA, Schalij MJ, Poelmann RE, Gittenberger-DE Groot AC, Jongbloed MR.

Electrical activation of sinus venosus myocardium and expression patterns of RhoA and Isl-1 in the chick embryo. J Cardiovasc Electrophysiol. 2010;21(11):1284-92. doi: 10.1111/j.15408167.2010.01790.x.

Vicente-Steijn R, Passier R, Wisse L, Schalij MJ, Poelmann RE, Gittenberger-de Groot AC, Jongbloed MR. Funny current channel HCN4 delineates the developing cardiac conduction system in chicken heart. Heart Rhythm. 2011;8(8):1254-63. doi:

10.1016/j.hrthm.2011.03.043

Villa Del Campo C, Lioux G, Carmona R, Sierra R, Muñoz-Chápuli R, Clavería C, Torres M. Myc overexpression enhances of epicardial contribution to the developing heart and promotes extensive expansion of the cardiomyocyte population. Sci Rep. 2016;6:35366. doi: 10.1038/srep35366. 
Vincent SD, Buckingham ME. How to make a heart: the origin and regulation of cardiac progenitor cells. Curr Top Dev Biol. 2010;90:1-41. doi: 10.1016/S0070-2153(10)90001-X

Wang J, Bai Y, Li N, Ye W, Zhang M, Greene SB, Tao Y, Chen Y, Wehrens XH, Martin JF. Pitx2microRNA pathway that delimits sinoatrial node development and inhibits predisposition to atrial fibrillation. Proc Natl Acad Sci U S A. 2014;111(25):9181-6. doi: 10.1073/pnas.1405411111.

Wiese C, Grieskamp T, Airik R, Mommersteeg MT, Gardiwal A, de Gier-de Vries C, SchusterGossler K, Moorman AF, Kispert A, Christoffels VM. Formation of the sinus node head and differentiation of sinus node myocardium are independently regulated by Tbx18 and Tbx3. Circ Res. 2009;104(3):388-97. doi: 10.1161/CIRCRESAHA.108.187062. I., 2009

Witzel HR, Cheedipudi S, Gao R, Stainier DY, Dobreva GD. Isl2b regulates anterior second heart field development in zebrafish. Sci Rep. 2017;7:41043. doi: 10.1038/srep41043.

Wu B, Zhang Z, Lui W, Chen X, Wang Y, Chamberlain AA, Moreno-Rodriguez RA, Markwald RR, O'Rourke BP, Sharp DJ, Zheng D, Lenz J, Baldwin HS, Chang CP, Zhou B. Endocardial cells form the coronary arteries by angiogenesis through myocardial-endocardial VEGF signaling. Cell. 2012;151(5):1083-96. doi: 10.1016/j.cell.2012.10.023.

Xie L, Hoffmann AD, Burnicka-Turek O, Friedland-Little JM, Zhang K, Moskowitz IP. Tbx5hedgehog molecular networks are essential in the second heart field for atrial septation. Dev Cell. 2012;23(2):280-91. doi: 10.1016/j.devcel.2012.06.006.

Ye W, Wang J, Song Y, Yu D, Sun C, Liu C, Chen F, Zhang Y, Wang F, Harvey RP, Schrader L, Martin JF, Chen Y. A common Shox2-Nkx2-5 antagonistic mechanism primes the pacemaker cell fate in the pulmonary vein myocardium and sinoatrial node. Development. 2015;142(14):2521-32. doi: 10.1242/dev.120220

Zaffran S, Kelly RG.New developments in the second heart field. Differentiation. 2012;84(1):1724. doi: 10.1016/j.diff.2012.03.003.

Zaffran S, El Robrini N, Bertrand N. Retinoids and Cardiac Development. J. Dev. Biol. 2014;2:5071; doi:10.3390/jdb2010050

Zhang H, Pu W, Li G, Huang X, He L, Tian X, Liu Q, Zhang L, Wu SM, Sucov HM, Zhou B. Endocardium Minimally Contributes to Coronary Endothelium in the Embryonic Ventricular Free Walls. Circ Res. 2016;118(12):1880-93. doi: 10.1161/CIRCRESAHA.116.308749. 
Figure legends

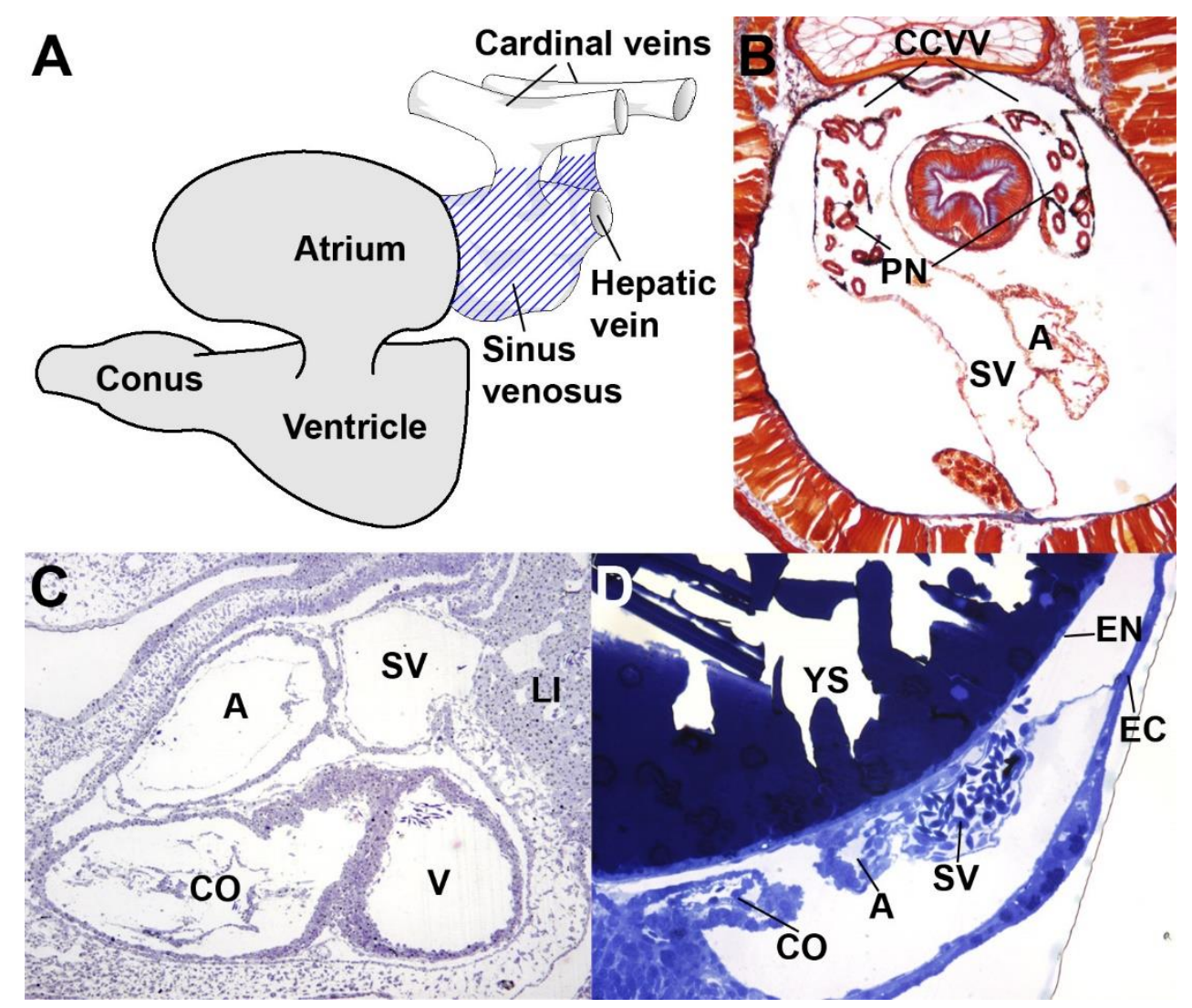

Figure 1. A. General organization of the four-chambered vertebrate heart. The sinus venosus (blue pattern) is composed of a central chamber and two lateral horns connected to the cardinal veins. 1-2 hepatic veins or a wide hepatic sinus also flow into the sinus venosus. B. Sinus venosus in the larva of a lamprey (Petromyzon). The large sinus venosus (SV) is located at the right of the atrium $(A)$ and receives blood from the right cardinal vein. Both cardinal veins (CCVV) are connected in the dorsal parte of the peritoneal cavity. The pronephros (PN) is located inside the cardinal veins in this species. C. Sagittal section of the heart of a dogfish shark embryo (Scyliorhinus) showing the four cardiac chambers typical of the vertebrate cardiac bauplan. The sinus venosus shows myocardial walls thinner than those of the atrium (A), ventricle (V) or conus (CO). D. Sagittal section of the heart of a zebrafish embryo (Brachydanio) showing the wide sinus venosus, the atrium and the conus. The ventricle is located at the right of the section plane. Note the lack of endothelial cells in the open space between endoderm (EN) and ectoderm (EC). LI: liver; YS: yolk sac. 


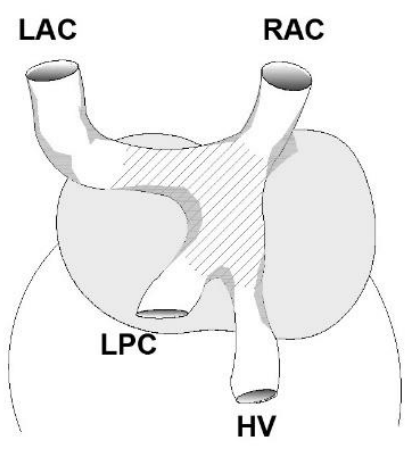

Amphibians and reptiles

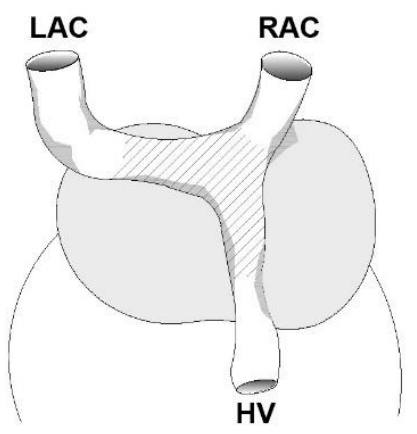

Birds

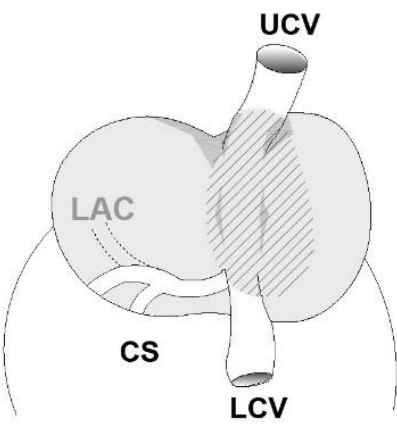

Mammals

Figure 2. Anatomy of the sinus venosus in adult tetrapods. The sinus venosus (stripped pattern) is a well-defined chamber in amphibians, reptiles and birds, receiving blood from the left and right anterior cardinal veins (LAC, RAC) and from the liver through the hepatic vein (HV). The left posterior cardinal vein can connect directly with the sinus venosus, but in many animals is captured by the hepatic return. In mammals the sinus venosus is incorporated to the atrial wall and the left anterior cardinal disappears or it can give rise to the coronary sinus (cardiac venous return). The hepatic and systemic return from the posterior part of the body arrives to the heart through the lower cava vein (LCV), while the anterior systemic return goes through the upper cava vein (UCV)derived from the right cardinal vein.

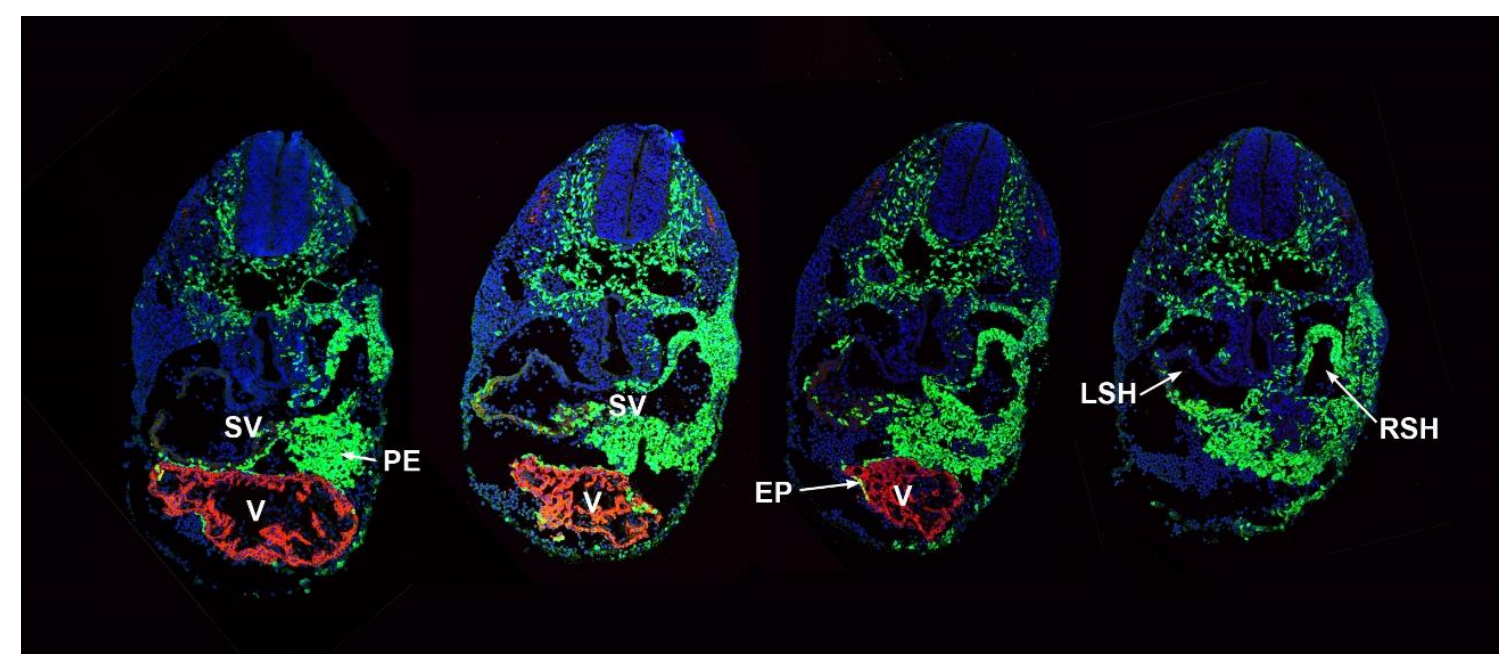

Figure 3. Transverse serial sections of the sinus venosus of an E9.5 mouse embryo (G2-

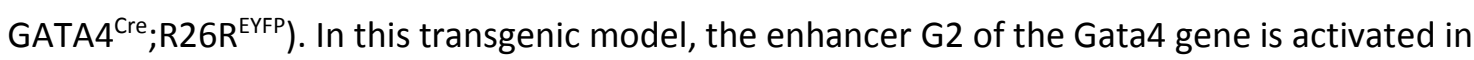
the lateral splanchnic mesoderm, and this cell lineage is labelled by the fluorescent protein EYFP. The sinus venosus shows a clear asymmetry, with a larger contribution at the right side. Note the lack of MF20 expression, since the myocardialization of the sinus venosus is not yet achieved. The proepicardium (PE) and the early epicardial cells (EP), but not the ventricle (V), belong to the same cell lineage. LSH, RSH: right and left sinus horns. 


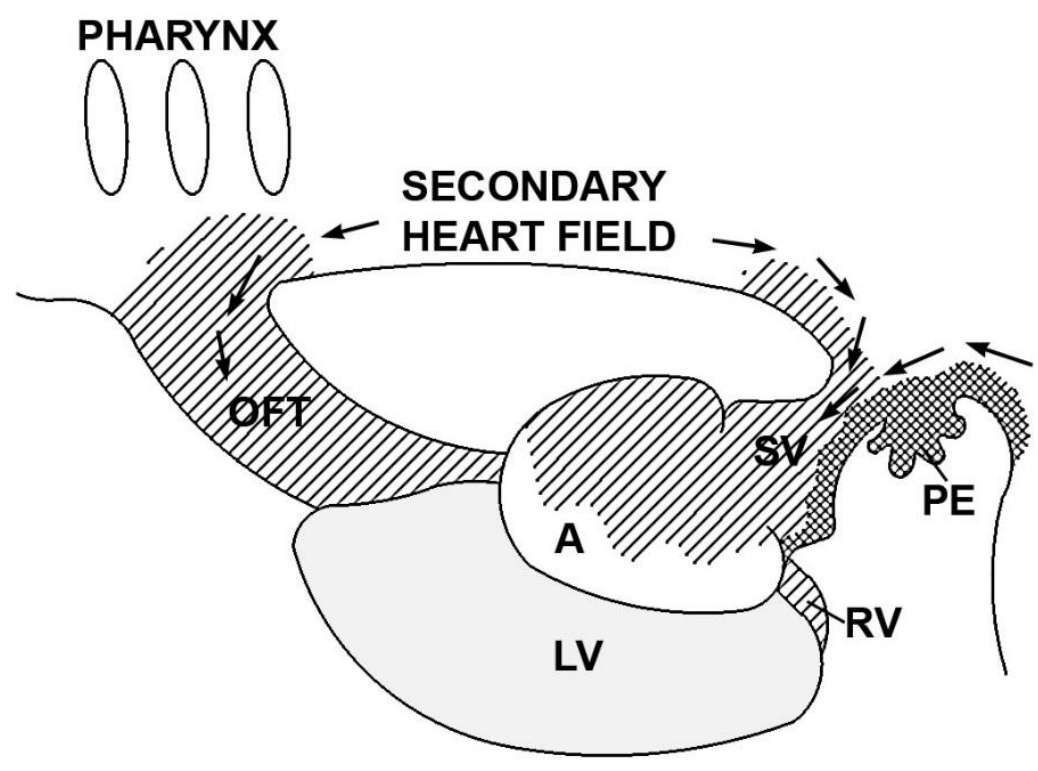

Figure 4. Derivatives of the secondary heart field. The pharyngeal mesoderm located on the dorsal pericardial wall migrates towards the anterior and posterior poles of the heart contributing to the outflow tract (OFT), and most of the right ventricle (RV), atria (A) and sinus venosus (SV) (stripped pattern). The posterior wall of the sinus venosus as well as the proepicardium (PE) derives from progenitors located more lateral and posteriorly (crossing diagonal pattern). LV: left ventricle.
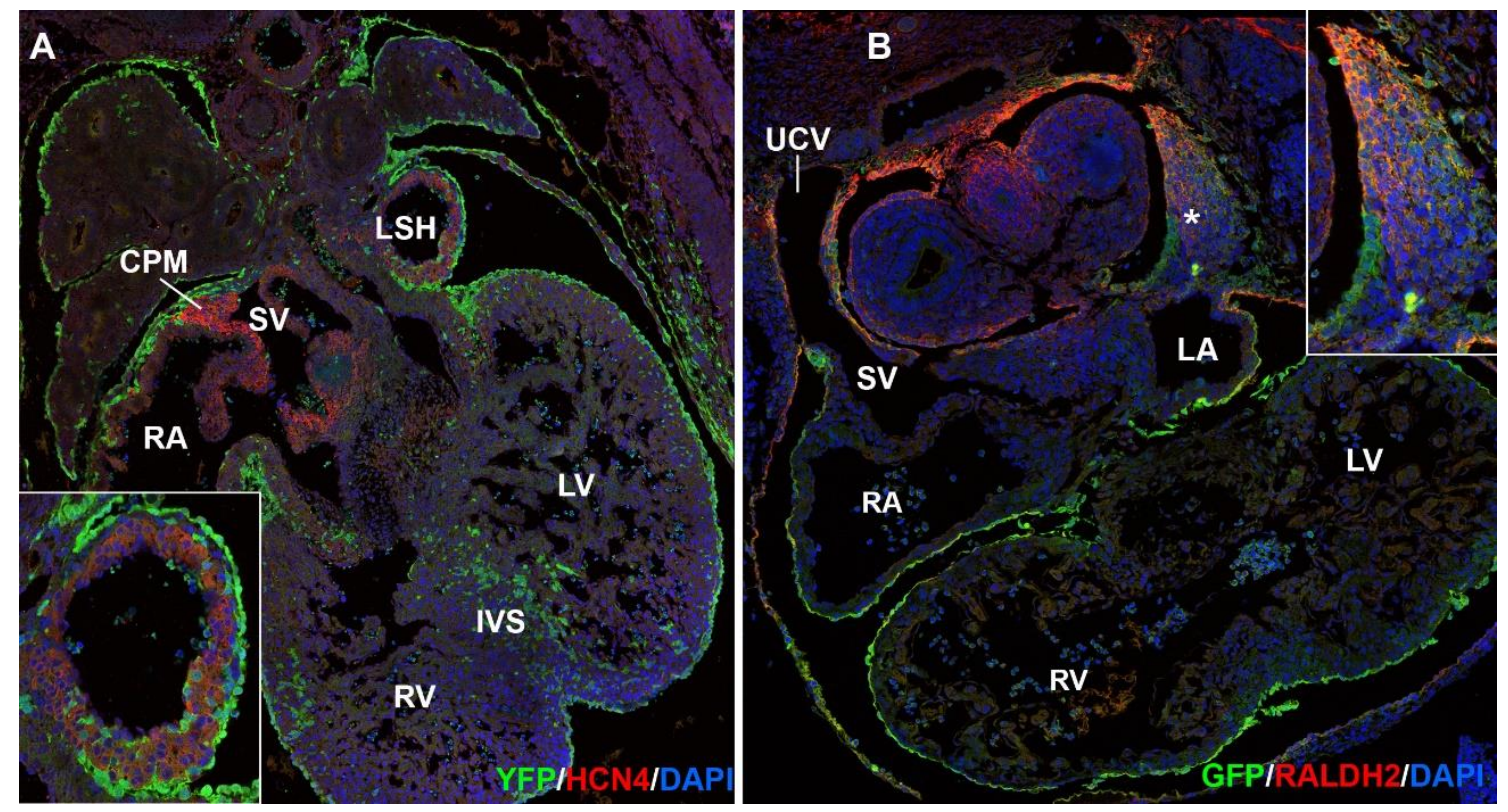

Figure 5. Wt1 expression in the cardiac inflow tract. A: Myocardial cells derived from a Wt1expressing lineage ( $\mathrm{Wt}^{\mathrm{Cre}} ; \mathrm{R} 26 \mathrm{R}^{\mathrm{EYFP}}$ murine model, E13.5 embryo) are located in the left sinus venosus horn (see insert) and interventricular septum (IVS), but they are not present in the cardiac pacemaker (CPM) identified by HCN4 expression (red). B: Wt1 ${ }^{\text {GFP }}$, E11.5 embryo. This is a reporter model for actual WT1 expression . Wt1 is expressed throughout the coelomic 
epithelium, including the epicardium) and walls of the cardinal veins where it colocalizes with Raldh2 expression. The asterisk shows the mesenchyme surrounding the wall of the upper left cardinal vein (see also insert at higher magnification). LA: left atrium; LV: left ventricle; RA:

right atrium; RV: right ventricle; SV: central part of the sinus venosus incorporated to the atrial wall.

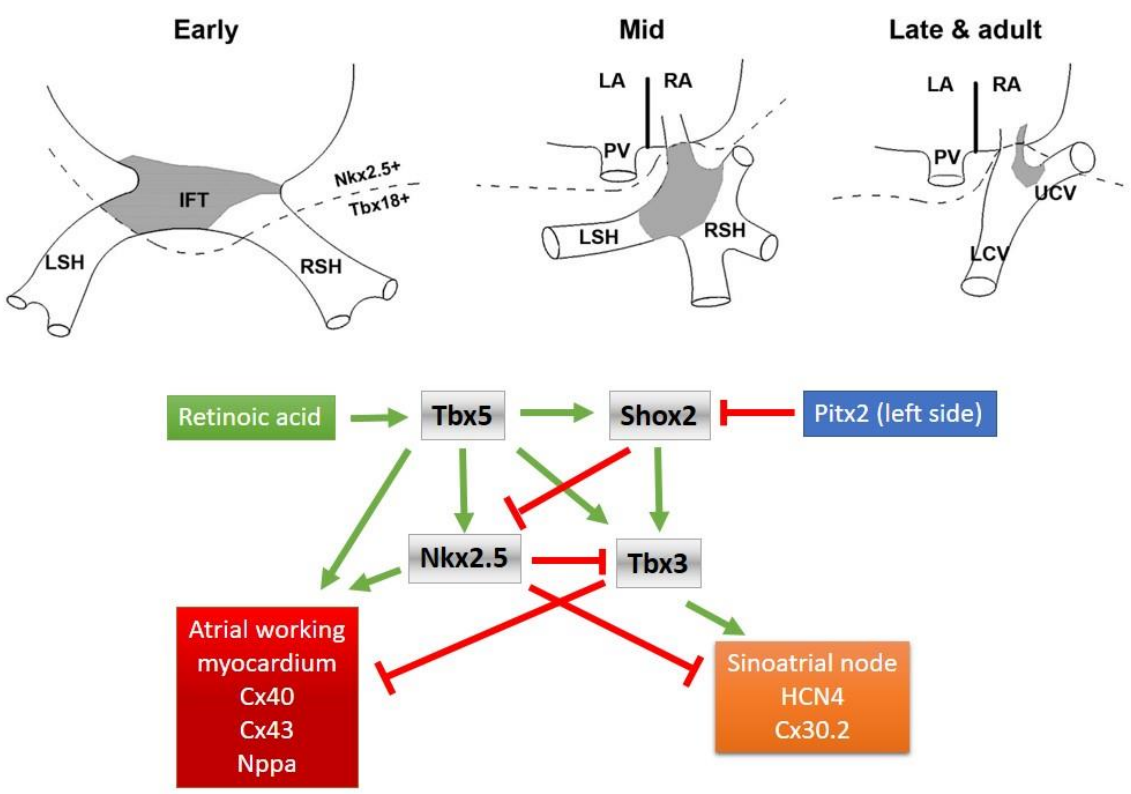

Figure 6. Pacemaker activity (stripped pattern) changes during development. The early pacemaker activity is located in the Tbx18-/Nkx2.5+ domain of the inflow tract (IFT), but it shifts by midgestion from a to a Tbx18+/Nkx2.5- domain of the right sinus horn (RSH), and finally it is restricted to the junction of the upper cava vein (UCV) with the right atrium (RA). The cartoon also shows the network of molecular interactions leading to sinoatrial node development and formation of the limits with the working myocardium of the atrium (based in Christoffels et al., 2010). LA: left atrium; LCV: lower cava vein; PV: pulmonary vein. 


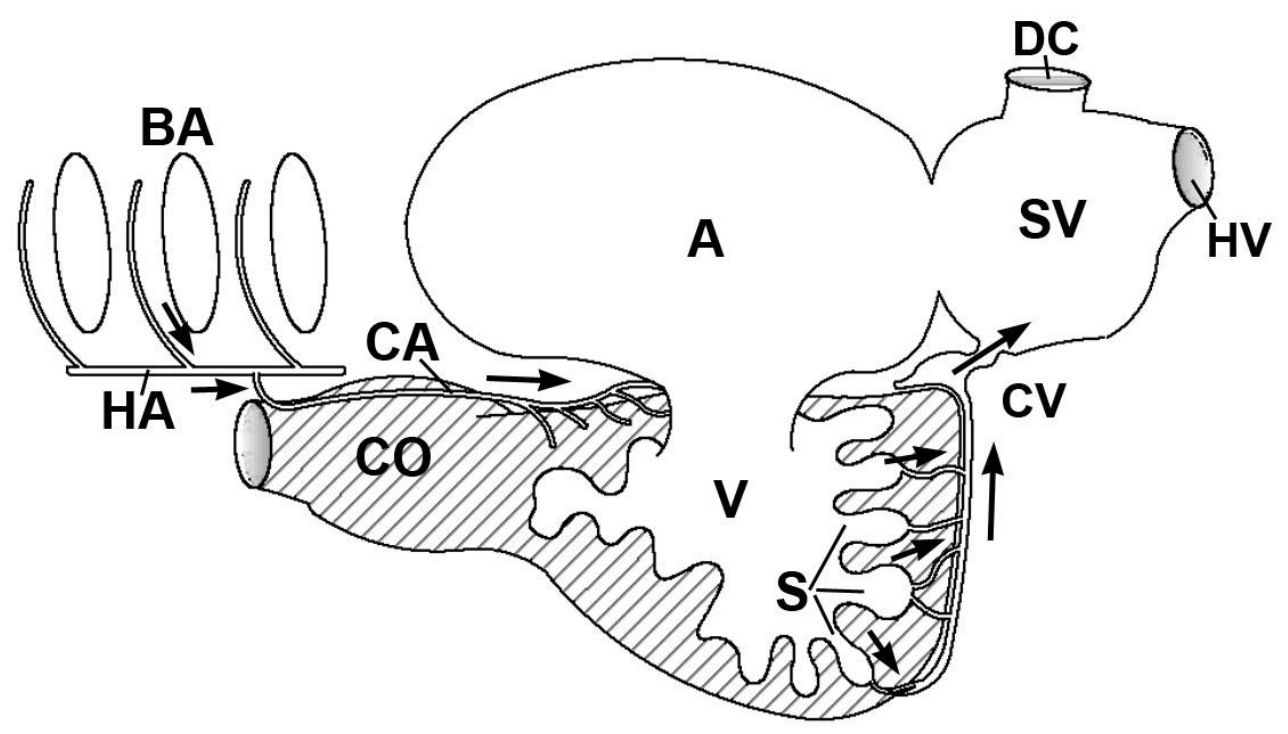

Figure 7. Model for the independent evolutionary origin of coronary arteries and cardiac veins. The cartoon shows the actual process of development of the cardiac vessels in the dogfish shark (Scyliorhinus) (De Andrés et al., 1993). Cardiac veins (CV) arise as sprouts of the sinus venosus (SV) endocardium, cover the ventricle and connect with the intertrabecular sinusoids (S) allowing for circulation of blood through the cardiac wall. Later, the hypobranchial artery (HA) gives rise to the coronary arteries (CA) that run over the conus arteriosus (CO) and supply oxygenated blood to the myocardium. The arrows show the direction of the blood flow. A: atrium; BA: Branchial arches; DC: Ducts of Cuvier; HV: Hepatic vein; V: ventricle. 